\title{
Discussion of Rapadas
}

\section{Transmission of Violence: Parallels to Latinos in the United States}

\author{
Albert Valencia \\ California State University, Fresno State, United States of America
}

\begin{abstract}
In his article, Dr Rapadas provides a serious and thoughtful look into the traumatisation of an indigeInous community. The article serves as a reminder of our history and as a call to those who believe that peace and justice are worthy and noble goals. The article also provides striking parallels to the struggles of Latinos, particularly Mexican Americans, in the United States.
\end{abstract}

Dr Rapadas presents a historical account describing the tragic, brutal, and long-term consequences of colonisation and wartime occupation. The people of Guam, the Native Chamoru, have endured 400 years of colonisation and exploitation, and, 32 months of wartime occupation. The article allows us to glimpse how the Native Chamoru suffered the trans-generational results of racism, oppression and injustice.

In an effort to conceptualise the effects and aftermath of the loss, devastation, and trauma inflicted upon the Chamoru, Dr Rapadas refers to the work of Becker (2004) and Blagg (2000). Listed among the factors for high rates of violence are marginalisation and dispossession, loss of land and traditional culture, breakdown of community kinship systems, and entrenched poverty. These factors are helpful in two ways. First, they help to understand the Chamoru colonisation experience and, second, they serve as a window to glimpse the Latino, and more specifically, the Mexican American experience in the United States (US).

For the victims of colonisation, Dr Rapadas writes that the PTSD (posttraumatic stress disorder) diagnostic label, created three decades ago to assist clinicians in their work with individuals, is not able to wholly conceptualise the experience of entire communities, cultures, and civilisations. Because the PTSD diagnosis cannot fully grasp the experiences of a traumatised indigenous community, Dr Rapadas presents a challenge for practitioners, theorists, and researchers in the field of psychology to move past the practice of using PTSD, and offers some alternate terms: rippled PTSD, as in the ripple effects from a stone dropped into a pool of water; postcolonialism stress disorder (PCSD); and, posttrauma transmission disorder (PTTD). For Mexican Americans in the US, it is also fitting to seek an alternative term that encompasses the historical and, perhaps more important, the continuing racist, economic, educational, social, and political stressors that confront Mexican Americans communities on a daily basis. Perhaps a term like continuous traumatic stress disorder (CTSD) can begin to account for the accumulated toxic trauma of cultural violence?

\section{The Onset of Colonisation}

In 1521, when Spanish warships 'discovered' Guam and proclaimed it a Spanish Crown territory, the process of colonisation began. Besides bringing themselves, the Spanish colonial effort also brought disease, famine, violence, and war. By 1850, only 3,500 Native Chamoru were counted as remaining. Dr Rapadas reports that today there exists no Native Chamoru of single descent on the island. The remaining 'mixed' Chamoru live with the humiliation of being marginalised and dispossessed from their land and culture, and entrenched in poverty and racism.

Chamoru have high-use rates of US federal entitlement programs, including food stamps, welfare, Medicaid, and Section 8 housing. Compared to other island ethnic groups, Chamoru have the highest rates of diabetes, obesity, hypertension, and cancer. In the past 20 years, Guam has reported increases in family violence, drug and alcohol abuse, and suicide. Dr Rapdadas writes that Chamoru are held responsible for the 
majority of reported crimes. Consequently, the Chamoru are over-represented in the drug and alcohol treatment facilities, and in the adult prisons and juvenile detention centres.

Dr Rapadas suggests that the societal ills in Guam have resulted, in part, from decades of unresolved trauma, violence, and unchecked colonial domination. He characterises the Chamoru as collectively victimised by a traumatic past, and as unable to overcome the damage, destruction, and loss of spirit throughout the centuries. Moreover, Dr Rapadas asserts that the historical colonising and occupation of Guam affects today's generation of Chamoru through the transmission of brutality, hatred, and violence within their own families.

\section{Parallels in the United States}

Colonial domination and the resulting societal ills perpetuated on the Native Chamoru have strikingly similar parallels in the US treatment of ethnic minorities and people of colour. African Americans, native Americans, Asian Americans and Latinos each have a detailed record of disgraceful treatment perpetuated by the US federal government, and by its associated state governments and agencies. For the following discussion, Latinos, particularly, Mexican Americans will be the focus.

Parallels exist in the consequences of colonial domination of Native Chamoru of Guam, and in the racist treatment of Latinos, most notably Mexican Americans in the US. As the land of the Chamoru was invaded, so too was the land of the Mexicans. This invasion resulted in war with the US. The Mexican War ended with the ratification by the US, on February 2, 1848, of the Treaty of Guadalupe Hidalgo (Conmy, 1948).

The Treaty of Guadalupe Hidalgo ceded $55 \%$ of the land comprising the Republic of Mexico to the United States, including the geography comprising Texas, Utah, Nevada, New Mexico, Arizona, Colorado, and California. The treaty promised that all privileges and guarantees, civil, political and religious would be enjoyed by any Mexican living in the territories included in lands ceded to the United States (Library of Congress, 2005). However, in terms of adhering to the treaty provisions, Mexican Americans have endured 150 years of societal and economic domination (Moreno, 1999) including a denial of property rights and having lands dispossessed. According to Haynes (2001) an accumulation of injustices based upon racist notions and fuelled by self-serving political and judicial institutions resulted in the dispossession of Mexican American landholders and in the concurrent enrichment of white America.

As with the Chamoru in Guam, there are two minority groups in the United States who were annexed by invasion. These two groups allegedly were to have their rights safeguarded by treaty. The two minority groups, Native Americans and Mexican Americans, both understand the consequences of promises made by a US Federal Government that practiced institutional racism, cultural myopia, and the narrow mindedness of the English-only linguistic chauvinism.

Since the signing of the Treaty of Guadalupe Hidalgo, Mexican Americans have experienced 15 decades of political and economic exploitation. Today, Latinos, and particularly Mexican Americans, represent one of the poorest ethnic minority groups in the United States, with at least one-third of all Latino families having incomes below the poverty level (Davis-Packard, 2000). The effects of poverty are manifested in California in many ways: $13 \%$ of all Latino children lack health insurance; 20\% lack dental insurance; 35\% are overweight (Children Now Report Card, 2005, p. 2-4) and $71 \%$ of Latina/o 4 th graders are eligible for free or reduced-price federal lunch programs (National Center for Education Statistics, 2004). In the US, up to $40 \%$ of Latino school age children will not graduate from high school (Children Now Report Card, 2005, p. 12) and are likely to inherit the trans-generational burdens of poverty, illiteracy, and frustration. Over the years these burdens were exacerbated, as students of Mexican descent in K-12 public schools were not allowed to speak Spanish and their history and traditions were not part of the public school curriculum. As the population of Mexican Americans reaches past 20 million, a continued underperformance in high school and college and subsequently of not being able to share and compete in the global market place is nothing less than an economic time bomb for the US (Valencia, 2002).

To make matters worse, there has been a recent emergence of vigilantism along the US-Mexico border, where US citizens have taken it upon themselves to patrol the border. Many see this action as another in a long line of disrespect directed at Mexicans and Mexican Americans. How the vigilantes, proudly calling themselves 'Americans', can stem the tide of migration from Mexico by sitting on lawn chairs and looking south through binoculars is unknown. Their bullying tactics appear pedestrian, yet their actions have attracted the attention of national news services. As insult to injury, some national, state, and local politicians support the appearance of these latter day Minutemen who ostensibly protect the border but are basically taking the law into their own hands. These same politicians turn the other way in restaurants, hotels, construction sites, and farm labour regions that rely heavily on the work provided by a pool of migrant Latino labourers that has been estimated at three million annually (Monto, 1994).

As the incidence of family violence increases in Guam, the trans-generational perpetuation of family violence is widespread among Mexican Americans in the US. However, until 1999, there existed no literature that presented a longitudinal look at violence in a large subject pool of Mexican American families (Valencia \& Van Hoorn, 1999). Equally alarming, the trans-generational perpetuation of gang violence increases each year 
until Brown-on-Brown murder, a Mexican American killing a Mexican American, becomes routine news in our newspapers. The spectre of street gang violence has migrated from the urban poor barrios to rural small towns without systematic acknowledgment from professional journals.

Poverty, poor housing, second class citizenship, abuse of alcohol and drugs, trans-generational family and gang violence, mind numbing school failure, alarming high school drop out rates, overrepresentation in prisons and jails, scant access to political power, and disappointing numbers of Latino college graduates are all part of the problem that needs to be studied. In an analysis of the 2000 US Census data, the 35,238,000 Latina/os who comprise $12 \%$, of the US population are projected to grow to $24 \%$ by 2050 (Ramirez, 2004; US Census Bureau, 2000). Certainly, to better understand the multitude of problems and to design effective prevention and intervention strategies, there is much work to be done.

According to the National Centre for Education Statistics (2003), in 2005 Latinos became the majority population in California, and they will continue to be underrepresented in both the ranks of high school students earning a diploma and college graduates. Somewhere we are missing a substantial link that would enable parents and their children to know that education can level the playing field for historically underrepresented populations. To aspire to high school and college graduation requires that Latina/os learn the educational context and to trust in the educational process. However, to trust in the process means that apologies for 150 years of neglect and exploitation must be offered so that people can forgive, reconcile, and move on.

Practitioners, theorists, and researchers interested in the lives of Mexican Americans, are struggling with models to respond to the issues that stem from the effects of racism, linguistic chauvinism, and cultural blindness. As Dr Rapadas points out, the road to peace and justice must include public apologies, so that forgiveness and reconciliation can emerge. After 400 years, Spain and Japan can begin the process of peace by offering public apologies for behaviour so unbecoming in Guam. The United States of America has also to offer public apologies for its behaviour. The US Congress held its first congressional hearing regarding reparations linked to the Treaty of Guadalupe Hidalgo 150 years after it was signed. One hundred and fifty years is a long time to wait; but 400 years is a lot longer. For our brothers and sisters in Guam, we say in Spanish 'no te dejes' (Don't back down!), and may the spirit of Emiliano Zapata be with you.

\section{References}

Becker, D. (2004, July 14). Trauma theorie. Dealing with the consequences of organized violence in trauma work (Ch. 2).
Retrieved February 9, 2006 from http://www.berghofhandbook.net/articles/becker_handbook.pdf

Blagg, H. (2000). Crisis intervention in Aboriginal family violence (Summary Rep.). Nedlands, Western Australia: University of Western Australia, Crime Research Centre. Retrieved February 15, 2006 from http://familyanddomesticviolence.communitydevelopment.wa.gov.au/content/pu bs/strategies_and_models.pdf.

Children Now Report Card (2005). California Report Card 2005. An assessment of children's well-being. Retrieved February 13, 2006 from http://publications.childrennow. org/publications/invest/reportcard_2005.cfm

Conmy, P.T. (1948). A centennial evaluation of the treaty of Guadalupe Hidalgo. Native Sons of the Golden West: Oakland, CA.

Davis-Packard, K. (2000). Era of prosperity largely skips Latino teens. Christian Science Monitor, 92, 3-5.

Haynes, J.M. (2001, Spring). The forgotten promises of the Treaty of Guadalupe Hidalgo. St Mary's law review on minority issues, 231-264, 232-236. Retrieved February 12, 2006, from http://academic.udayton.edu/race/ 02rights/guadalu7.htm

Library of Congress (2005). Teaching with documents: The Treaty of Guadalupe Hidalgo. National Archives. Retrieved February 15, 2006 from http://www.archives.gov/ education/lessons/guadalupe-hidalgo/

Monto, A. (1994). The roots of Mexican labor migration. Westport, CT: Greenwood.

Moreno, J. (1999). The elusive quest for equality: 150 years of Chicano/Chicana education. Harvard Educational Review Reprint Series No. 32. ERIC Document: \#ED449926

National Center for Education Statistics (2003). Status and trends in the education of Hispanics, executive summary. US Department of Education, Institute of Education Sciences. Retrieved February 15, 2006 from http://nces.ed.gov/pubs2003/hispanics/

National Center for Education Statistics (2004). Participation in education: Elementary/secondary education. US Department of Education. Institute of Education Sciences. Retrieved February 15, 2006 from http://nces.ed.gov/programs/coe/2004/section1/indicator05.asp

Ramirez, R. (2004, December). US Census 2000 Special Report. We the people - Hispanics in the US. US Census Bureau. Retrieved February 10, 2006 from www.census.gov/ prod/2004pubs/censr-18.pdf

US Census Bureau (2000). US interim projections by age, sex, race, and Hispanic origin. Summary Table 1a, PDF (87K) file. Retrieved February 15, 2006 from http://www.census. gov/ipc/www/usinterimproj/

Valencia, A. (April, 2002). Decreasing Latina/o university dropouts. Hispanic Outlook in Higher Education, p. 68.

Valencia, A., \& Van Hoorn, J. (1999). La Isla Pacifica: A haven for battered Mexican American women. American Psychologist, 54, 62-63. 